\title{
PRESENTASI SUBGRUP DARI REPRESENTASI GRUP QUATERNION DAN HASILKALI KRONECKER
}

\author{
ROZI FAUZI, YANITA, MONIKA RIANTI HELMI \\ Program Studi S1 Matematika, \\ Fakultas Matematika dan Ilmu Pengetahuan Alam, Universitas Andalas, \\ Kampus UNAND Limau Manis Padang, Indonesia. \\ email : rozifauzi4@gmail.com
}

Diterima 9 Maret 2019 Direvisi 7 April 2019 Dipublikasikan 7 Mei 2019

\begin{abstract}
Abstrak. Grup dari representasi grup quaternion dan hasilkali Kronecker memiliki banyak subgrup. Setiap grup maupun subgrup dapat dibentuk dalam bentuk presentasi grup. Dalam tulisan ini akan membahas presentasi grup sejati dari representasi grup quaternion dan hasilkali Kronecker. Presentasi grup adalah suatu cara mendefinisikan grup dengan menggunakan generator dan relasi. Subgrup yang terdapat pada grup dari representasi grup quaternion dan hasilkali Kronecker akan dikelompokkan berdasarkan kesamaan perkalian unsur pada tabel perkalian grup, setelah itu akan dibentuk presentasi subgrup dengan memperhatikan sifat dari masing-masing unsur dalam subgrup tersebut. Pada penelitian ini diperoleh sebanyak delapan kesamaan kelompok subgrup berdasarkan kesamaan perkalian unsur pada tabel perkalian grup. Hal ini mengakibatkan terdapat sebanyak delapan presentasi subgrup berdasarkan kelompok yang telah diperoleh.

Kata Kunci: Grup dari Representasi Grup Quaternion dan Hasil kali Kronecker, Presentasi grup
\end{abstract}

\section{Pendahuluan}

Grup adalah suatu himpunan tak kosong yang dilengkapi dengan suatu operasi yang memenuhi sifat asosiatif, memiliki unsur satuan, dan memiliki balikan(invers). Sedangkan, subgrup adalah subhimpunan atau himpunan bagian dari suatu grup dengan operasi biner yang sama dengan grup tersebut dan memiliki balikan pada subgrup itu sendiri. Setiap grup dan subgrup dapat dibentuk dalam bentuk presentasi grup. Presentasi grup adalah himpunan relasi yang harus dipenuhi oleh unsur pembangun grup, yang menggambarkan isi dari grup berdasarkan relasi dan unsur pembangunnya.

Salah satu sistem matematika yang memenuhi sifat-sifat grup yaitu grup quaternion. Grup quaternion adalah grup tak komutatif berorde delapan yang didefinisikan dari unsur quaternion yang ditemukan oleh Sir Wiliam Hamilton pada tahun 1843 [9]. Pada tahun 2018, Yanita, dkk [2] mengkaji suatu grup berdasarkan definisi grup quaternion di atas dan diperoleh grup dari representasi grup quaternion dan hasilkali Kronecker tersebut. Representasi adalah suatu homomorfisma grup dari 
$G$ ke suatu grup dari matriks berukuran $n \times n$ yang memiliki invers [8]. Hasilkali Kronecker adalah suatu operasi matriks yang disimbolkan dengan $\otimes$ dan didefinisikan dengan $A \otimes B=\left[a_{i j} B\right]$ dimana $A$ adalah matriks berukuran $m \times n, B$ adalah matriks berukuran $p \times q$ dan $A \otimes B$ adalah matriks berukuran $m p \times n q$ [6]. Grup ini merupakan grup berorde 32 dan memiliki subgrup-subgrup berorde dua, empat, delapan dan enam belas. Tulisan ini akan membahas tentang presentasi subgrup sejati dari representasi grup quaternion dan hasilkali Kronecker.

\section{Tinjauan Pustaka}

\subsection{Grup}

Definisi 2.1. [1] Suatu grup yang ditulis $(G, *)$, dimana $G$ adalah suatu himpunan dan $*$ adalah operasi biner pada $G$ memenuhi aturan berikut :

(1) $(a * b) * c=a *(b * c)$ untuk setiap unsur $a, b, c \in G$ (Dengan kata lain $*$ asosiatif).

(2) Terdapat suatu unsur e di $G$ yang memenuhi $a * e=e * a=a$ untuk semua unsur a di $G$. (e disebut identitas dari $G$ ).

(3) Untuk setiap $a \in G$, terdapat unsur $a^{-1}$ di $G$ yang memenuhi $a * a^{-1}=a^{-1} * a=$ e. $\left(a^{-1}\right.$ disebut invers dari a).

Selanjutnya untuk memudahkan, penulisan $a * b$ ditulis sebagai $a b$.

Definisi 2.2. [1] Grup $G$ dikatakan abelian atau komutatif jika $a b=b a$ untuk setiap $a, b \in G$.

Untuk suatu grup $G$ berhingga, orde dari $G$ disebut sebagai kardinalitas dari $G$ dan disimbolkan dengan $\circ(G)$ atau $|G|$ [4]. Pada grup $G$, bentuk $a^{n}(a \in G, n \in \mathbb{Z})$ didefinisikan sebagai berikut:

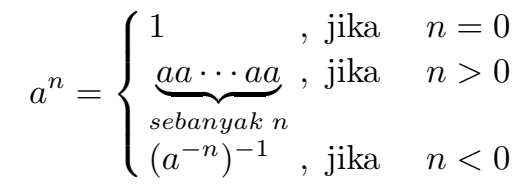

Operasi $a^{n}$ disini bergantung pada operasi biner yang ada pada grup.

Definisi 2.3. [1] Misalkan $G$ suatu grup. Suatu subhimpunan $H$ dari $G$ adalah subgrup dari $G$ jika $H$ adalah bukan himpunan kosong dan $H$ tertutup terhadap operasi dan inversnya (dengan kata lain $x, y \in H$ berarti $x^{-1} \in H$ dan $x y \in H$. Jika $H$ adalah subgrup dari $G$ ditulis $H \leq G$.

Proposisi 2.4. [1] Suatu subhimpunan $H$ dari suatu grup $G$ adalah subgrup jika dan hanya jika :

(1) $H \neq \emptyset$ dan

(2) Untuk setiap $x, y \in H$ berlaku $x y^{-1} \in H$.

Misalkan $G$ suatu grup, dimana unsur identitas adalah subgrup trivial dan grup $G$ itu sendiri adalah subgrup pada grup $G$ yang disebut subgrup tak sejati, sedangkan subgrup-subgrup lainnya disebut subgrup sejati. 


\subsection{Matriks}

Definisi 2.5. [7] Matriks didefinisikan sebagai susunan persegi panjang dari bilangan-bilangan yang diatur dalam barisan-barisan dan kolom-kolom.

Matriks ditulis sebagai berikut :

$$
\left[\begin{array}{cccc}
a_{11} & a_{12} & \cdots & a_{1 n} \\
a_{21} & a_{22} & \cdots & a_{2 n} \\
\vdots & & & \vdots \\
a_{m 1} & a_{m 2} & \cdots & a_{m n}
\end{array}\right]
$$

Urutan di atas disebut matriks $m \times n$ karena memiliki $m$ barisan dan $n$ kolom. Sebagai aturan kurung siku [], kurung () atau bentuk || || digunakan untuk mengurungi aturan persegi panjang dari bilangan-bilangan [7].

Definisi 2.6. [7] Jika diberikan sebuah matriks $A$ berukuran $m \times n$ dan sebuah matriks $B$ berukuran $n \times r$, hasilkali $A B$ didefinisikan sebagai matriks $C$ berukuran $m \times r$ yang unsurnya dihitung dari elemen-elemen $A, B$ menurut

$$
c_{i j}=\sum_{1 \leq k \leq n} a_{i k} b_{k j}, i=1,2, \cdots, m, j=1,2, \cdots, r .
$$

\subsection{Grup dari Representasi Grup Quaternion dan Hasilkali Kronecker}

Grup dari representasi grup quaternion dan hasilkali Kronecker dipe-roleh dengan mengaplikasikan hasilkali Kronecker pada unsur-unsur dari grup quaternion yang direpresentasikan dalam bentuk matriks. Grup ini merupakan grup berorde 32 dengan unsur-unsurnya adalah sebagai berikut :[4]

$$
\begin{aligned}
& A_{1}=\left[\begin{array}{llll}
1 & 0 & 0 & 0 \\
0 & 1 & 0 & 0 \\
0 & 0 & 1 & 0 \\
0 & 0 & 0 & 1
\end{array}\right], A_{2}=\left[\begin{array}{cccc}
-1 & 0 & 0 & 0 \\
0 & -1 & 0 & 0 \\
0 & 0 & -1 & 0 \\
0 & 0 & 0 & -1
\end{array}\right], A_{3}=\left[\begin{array}{cccc}
i & 0 & 0 & 0 \\
0 & -i & 0 & 0 \\
0 & 0 & i & 0 \\
0 & 0 & 0 & -i
\end{array}\right], A_{4}=\left[\begin{array}{cccc}
-i & 0 & 0 & 0 \\
0 & i & 0 & 0 \\
0 & 0 & -i & 0 \\
0 & 0 & 0 & i
\end{array}\right], \\
& A_{5}=\left[\begin{array}{cccc}
0 & 1 & 0 & 0 \\
-1 & 0 & 0 & 0 \\
0 & 0 & 0 & 1 \\
0 & 0 & -1 & 0
\end{array}\right], A_{6}=\left[\begin{array}{cccc}
0 & -1 & 0 & 0 \\
1 & 0 & 0 & 0 \\
0 & 0 & 0 & -1 \\
0 & 0 & 1 & 0
\end{array}\right], A_{7}=\left[\begin{array}{cccc}
0 & i & 0 & 0 \\
i & 0 & 0 & 0 \\
0 & 0 & 0 & i \\
0 & 0 & i & 0
\end{array}\right], A_{8}=\left[\begin{array}{cccc}
0 & -i & 0 & 0 \\
-i & 0 & 0 & 0 \\
0 & 0 & 0 & -i \\
0 & 0 & -i & 0
\end{array}\right] \text {, } \\
& A_{9}=\left[\begin{array}{cccc}
i & 0 & 0 & 0 \\
0 & i & 0 & 0 \\
0 & 0 & -i & 0 \\
0 & 0 & 0 & -i
\end{array}\right], A_{10}=\left[\begin{array}{cccc}
-i & 0 & 0 & 0 \\
0 & -i & 0 & 0 \\
0 & 0 & i & 0 \\
0 & 0 & 0 & i
\end{array}\right], A_{11}=\left[\begin{array}{cccc}
-1 & 0 & 0 & 0 \\
0 & 1 & 0 & 0 \\
0 & 0 & 1 & 0 \\
0 & 0 & 0 & -1
\end{array}\right], A_{12}=\left[\begin{array}{cccc}
1 & 0 & 0 & 0 \\
0 & -1 & 0 & 0 \\
0 & 0 & -1 & 0 \\
0 & 0 & 0 & 1
\end{array}\right], \\
& A_{13}=\left[\begin{array}{cccc}
0 & i & 0 & 0 \\
-i & 0 & 0 & 0 \\
0 & 0 & 0 & -i \\
0 & 0 & i & 0
\end{array}\right], A_{14}=\left[\begin{array}{cccc}
0 & -i & 0 & 0 \\
i & 0 & 0 & 0 \\
0 & 0 & 0 & i \\
0 & 0 & -i & 0
\end{array}\right], A_{15}=\left[\begin{array}{cccc}
0 & -1 & 0 & 0 \\
-1 & 0 & 0 & 0 \\
0 & 0 & 0 & 1 \\
0 & 0 & 1 & 0
\end{array}\right], A_{16}=\left[\begin{array}{cccc}
0 & 1 & 0 & 0 \\
1 & 0 & 0 & 0 \\
0 & 0 & 0 & -1 \\
0 & 0 & -1 & 0
\end{array}\right] \text {, }
\end{aligned}
$$


Presentasi Subgrup dari Representasi Grup Quaternion dan Hasilkali Kronecker 131

$$
\begin{aligned}
& A_{17}=\left[\begin{array}{cccc}
0 & 0 & 1 & 0 \\
0 & 0 & 0 & 1 \\
-1 & 0 & 0 & 0 \\
0 & -1 & 0 & 0
\end{array}\right], A_{18}=\left[\begin{array}{cccc}
0 & 0 & -1 & 0 \\
0 & 0 & 0 & -1 \\
1 & 0 & 0 & 0 \\
0 & 1 & 0 & 0
\end{array}\right], A_{19}=\left[\begin{array}{cccc}
0 & 0 & i & 0 \\
0 & 0 & 0 & -i \\
-i & 0 & 0 & 0 \\
0 & i & 0 & 0
\end{array}\right], A_{20}=\left[\begin{array}{cccc}
0 & 0 & -i & 0 \\
0 & 0 & 0 & i \\
i & 0 & 0 & 0 \\
0 & -i & 0 & 0
\end{array}\right], \\
& A_{21}=\left[\begin{array}{cccc}
0 & 0 & 0 & 1 \\
0 & 0 & -1 & 0 \\
0 & -1 & 0 & 0 \\
1 & 0 & 0 & 0
\end{array}\right], A_{22}=\left[\begin{array}{cccc}
0 & 0 & 0 & -1 \\
0 & 0 & 1 & 0 \\
0 & 1 & 0 & 0 \\
-1 & 0 & 0 & 0
\end{array}\right], A_{23}=\left[\begin{array}{cccc}
0 & 0 & 0 & i \\
0 & 0 & i & 0 \\
0 & -i & 0 & 0 \\
-i & 0 & 0 & 0
\end{array}\right], A_{24}=\left[\begin{array}{cccc}
0 & 0 & 0 & -i \\
0 & 0 & -i & 0 \\
0 & i & 0 & 0 \\
i & 0 & 0 & 0
\end{array}\right],
\end{aligned}
$$

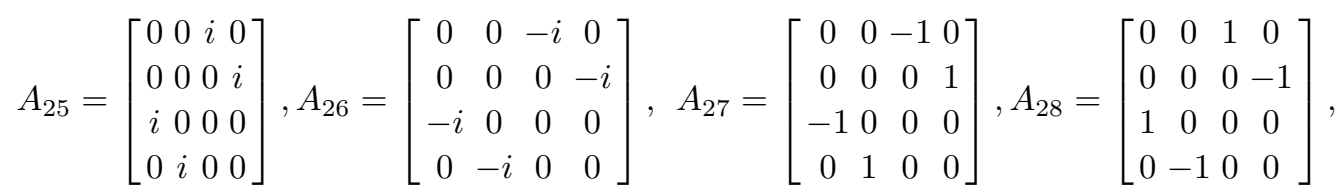

$$
\begin{aligned}
& A_{29}=\left[\begin{array}{cccc}
0 & 0 & 0 & i \\
0 & 0 & -i & 0 \\
0 & i & 0 & 0 \\
-i & 0 & 0 & 0
\end{array}\right], A_{30}=\left[\begin{array}{cccc}
0 & 0 & 0 & -i \\
0 & 0 & i & 0 \\
0 & -i & 0 & 0 \\
i & 0 & 0 & 0
\end{array}\right], A_{31}=\left[\begin{array}{cccc}
0 & 0 & 0 & -1 \\
0 & 0 & -1 & 0 \\
0 & -1 & 0 & 0 \\
-1 & 0 & 0 & 0
\end{array}\right], A_{32}=\left[\begin{array}{llll}
0 & 0 & 0 & 1 \\
0 & 0 & 1 & 0 \\
0 & 1 & 0 & 0 \\
1 & 0 & 0 & 0
\end{array}\right] .
\end{aligned}
$$

Berikut adalah subgrup dari representasi grup quaternion dan hasilkali Kronecker.

(1) Subgrup berorde 1.

$$
H_{0}=\left\{A_{1}\right\}
$$

(2) Subgrup berode 2.

$$
\begin{aligned}
& H_{1}=\left\{A_{1}, A_{2}\right\}, \quad H_{2}=\left\{A_{1}, A_{11}\right\}, H_{3}=\left\{A_{1}, A_{12}\right\}, H_{4}=\left\{A_{1}, A_{13}\right\}, \\
& H_{5}=\left\{A_{1}, A_{14}\right\}, H_{6}=\left\{A_{1}, A_{15}\right\}, H_{7}=\left\{A_{1}, A_{16}\right\}, H_{8}=\left\{A_{1}, A_{19}\right\}, \\
& H_{9}=\left\{A_{1}, A_{20}\right\}, H_{10}=\left\{A_{1}, A_{21}\right\}, H_{11}=\left\{A_{1}, A_{22}\right\}, H_{12}=\left\{A_{1}, A_{23}\right\}, \\
& H_{13}=\left\{A_{1}, A_{24}\right\}, H_{14}=\left\{A_{1}, A_{27}\right\}, H_{15}=\left\{A_{1}, A_{28}\right\}, H_{16}=\left\{A_{1}, A_{29}\right\}, \\
& H_{17}=\left\{A_{1}, A_{30}\right\}, H_{18}=\left\{A_{1}, A_{31}\right\}, H_{19}=\left\{A_{1}, A_{32}\right\}
\end{aligned}
$$

(3) Subgrup berorde 4 .

$$
\begin{aligned}
& H_{20}=\left\{A_{1}, A_{2}, A_{3}, A_{4}\right\}, \quad H_{21}=\left\{A_{1}, A_{2}, A_{5}, A_{6}\right\}, H_{22}=\left\{A_{1}, A_{2}, A_{7}, A_{8}\right\}, \\
& H_{23}=\left\{A_{1}, A_{2}, A_{9}, A_{10}\right\}, H_{24}=\left\{A_{1}, A_{2}, A_{11}, A_{12}\right\}, H_{25}=\left\{A_{1}, A_{2}, A_{13}, A_{14}\right\}, \\
& H_{26}=\left\{A_{1}, A_{2}, A_{15}, A_{16}\right\}, H_{27}=\left\{A_{1}, A_{2}, A_{17}, A_{18}\right\}, H_{28}=\left\{A_{1}, A_{2}, A_{19}, A_{20}\right\}, \\
& H_{29}=\left\{A_{1}, A_{2}, A_{21}, A_{22}\right\}, H_{30}=\left\{A_{1}, A_{2}, A_{23}, A_{24}\right\}, H_{31}=\left\{A_{1}, A_{2}, A_{25}, A_{26}\right\}, \\
& H_{32}=\left\{A_{1}, A_{2}, A_{27}, A_{28}\right\}, H_{33}=\left\{A_{1}, A_{2}, A_{29}, A_{30}\right\}, H_{34}=\left\{A_{1}, A_{2}, A_{31}, A_{32}\right\} .
\end{aligned}
$$

(4) Subgrup berorde 8 .

$$
\begin{aligned}
& H_{35}=\left\{A_{1}, A_{2}, A_{3}, A_{4}, A_{5}, A_{6}, A_{7}, A_{8}\right\}, \quad H_{53}=\left\{A_{1}, A_{2}, A_{7}, A_{8}, A_{27}, A_{28}, A_{29}, A_{30}\right\}, \\
& H_{36}=\left\{A_{1}, A_{2}, A_{3}, A_{4}, A_{9}, A_{10}, A_{11}, A_{12}\right\}, H_{54}=\left\{A_{1}, A_{2}, A_{9}, A_{10}, A_{17}, A_{18}, A_{25}, A_{26}\right\}, \\
& H_{37}=\left\{A_{1}, A_{2}, A_{3}, A_{4}, A_{13}, A_{14}, A_{15}, A_{16}\right\}, H_{55}=\left\{A_{1}, A_{2}, A_{9}, A_{10}, A_{19}, A_{20}, A_{27}, A_{28}\right\}, \\
& H_{38}=\left\{A_{1}, A_{2}, A_{3}, A_{4}, A_{17}, A_{18}, A_{19}, A_{20}\right\}, H_{56}=\left\{A_{1}, A_{2}, A_{9}, A_{10}, A_{21}, A_{22}, A_{29}, A_{30}\right\}, \\
& H_{39}=\left\{A_{1}, A_{2}, A_{3}, A_{4}, A_{21}, A_{22}, A_{23}, A_{24}\right\}, H_{57}=\left\{A_{1}, A_{2}, A_{9}, A_{10}, A_{23}, A_{24}, A_{31}, A_{32}\right\}, \\
& H_{40}=\left\{A_{1}, A_{2}, A_{3}, A_{4}, A_{25}, A_{26}, A_{27}, A_{28}\right\}, H_{58}=\left\{A_{1}, A_{2}, A_{11} A_{12}, A_{17}, A_{18}, A_{27}, A_{28}\right\},
\end{aligned}
$$


$H_{41}=\left\{A_{1}, A_{2}, A_{3}, A_{4}, A_{29}, A_{30}, A_{31}, A_{32}\right\}, H_{59}=\left\{A_{1}, A_{2}, A_{11} A_{12}, A_{19}, A_{20}, A_{25}, A_{26}\right\}$, $H_{42}=\left\{A_{1}, A_{2}, A_{5}, A_{6}, A_{9}, A_{10}, A_{13}, A_{14}\right\}, H_{60}=\left\{A_{1}, A_{2} A_{11}, A_{12}, A_{21}, A_{22} A_{31}, A_{32}\right\}$, $H_{43}=\left\{A_{1}, A_{2}, A_{5}, A_{6}, A_{11}, A_{12}, A_{15}, A_{16}\right\}, H_{61}=\left\{A_{1}, A_{2} A_{11}, A_{12}, A_{23}, A_{24} A_{29}, A_{30}\right\}$, $H_{44}=\left\{A_{1}, A_{2}, A_{5}, A_{6}, A_{17}, A_{18}, A_{21}, A_{22}\right\}, H_{62}=\left\{A_{1}, A_{2} A_{13}, A_{14}, A_{17}, A_{18} A_{29}, A_{30}\right\}$, $H_{45}=\left\{A_{1}, A_{2}, A_{5}, A_{6}, A_{19}, A_{20}, A_{23}, A_{24}\right\}, H_{63}=\left\{A_{1}, A_{2} A_{13}, A_{14}, A_{19}, A_{20} A_{31}, A_{32}\right\}$, $H_{46}=\left\{A_{1}, A_{2}, A_{5}, A_{6}, A_{25}, A_{26}, A_{29}, A_{30}\right\}, H_{64}=\left\{A_{1}, A_{2} A_{13}, A_{14}, A_{21}, A_{22} A_{25}, A_{26}\right\}$, $H_{47}=\left\{A_{1}, A_{2}, A_{5}, A_{6}, A_{27}, A_{28}, A_{31}, A_{32}\right\}, H_{65}=\left\{A_{1}, A_{2} A_{13}, A_{14}, A_{23}, A_{24} A_{27}, A_{28}\right\}$, $H_{48}=\left\{A_{1}, A_{2}, A_{7}, A_{8}, A_{9}, A_{10}, A_{15}, A_{16}\right\}, H_{66}=\left\{A_{1}, A_{2} A_{15}, A_{16}, A_{17}, A_{18} A_{31}, A_{32}\right\}$, $H_{49}=\left\{A_{1}, A_{2}, A_{7}, A_{8}, A_{11}, A_{12}, A_{13}, A_{14}\right\}, H_{67}=\left\{A_{1}, A_{2} A_{15}, A_{16}, A_{19}, A_{20} A_{29}, A_{30}\right\}$, $H_{50}=\left\{A_{1}, A_{2}, A_{7}, A_{8}, A_{17}, A_{18}, A_{23}, A_{24}\right\}, H_{68}=\left\{A_{1}, A_{2} A_{15}, A_{16}, A_{21}, A_{22} A_{27}, A_{28}\right\}$, $H_{51}=\left\{A_{1}, A_{2}, A_{7}, A_{8}, A_{19}, A_{20}, A_{21}, A_{22}\right\}, H_{69}=\left\{A_{1}, A_{2} A_{15}, A_{16}, A_{23}, A_{24} A_{25}, A_{26}\right\}$, $H_{52}=\left\{A_{1}, A_{2}, A_{7}, A_{8}, A_{25}, A_{26}, A_{31}, A_{32}\right\}$.

(5) Subgrup berorde 16.

$$
\begin{aligned}
& H_{70}=\left\{A_{1}, A_{2} A_{3}, A_{4}, A_{5}, A_{6} A_{7}, A_{8}, A_{9}, A_{10} A_{11}, A_{12}, A_{13}, A_{14} A_{15}, A_{16}\right\}, \\
& H_{71}=\left\{A_{1}, A_{2} A_{3}, A_{4}, A_{5}, A_{6} A_{7}, A_{8}, A_{17}, A_{18} A_{19}, A_{20}, A_{21}, A_{22} A_{23}, A_{24}\right\}, \\
& H_{72}=\left\{A_{1}, A_{2} A_{3}, A_{4}, A_{5}, A_{6} A_{7}, A_{8}, A_{25} A_{26}, A_{27}, A_{28}, A_{29} A_{30}, A_{31}, A_{32}\right\}, \\
& H_{73}=\left\{A_{1}, A_{2} A_{5}, A_{6}, A_{9}, A_{10} A_{13}, A_{14}, A_{17} A_{18}, A_{21}, A_{22}, A_{25} A_{26}, A_{39}, A_{30}\right\} .
\end{aligned}
$$

(6) Subgrup berorde 32 .

$$
H_{74}=G
$$

\subsection{Relasi}

Definisi 2.7. [5] Misalkan $A$ dan $B$ adalah himpunan. Himpunan $A \times B=\{(a, b) \mid$ $a \in A, b \in B\}$ disebut hasilkali kartesian dari himpunan $A$ dan $B$.

Definisi 2.8. [5] Misalkan $A$ dan $B$ adalah himpunan. Relasi $R$ pada $A$ dan $B$ adalah himpunan bagian dari hasilkali kartesian $A \times B$.

Kasus yang paling banyak ditemui dalam pembelajaran mengenai relasi adalah ketika himpunan $A=B$ sehingga relasi $R$ pada $A$ adalah himpunan bagian dari hasilkali kartesian $A \times A$.

Definisi 2.9. [5] Misalkan $A$ adalah himpunan dan $R$ adalah relasi pada $A$. $R$ dikatakan refleksif jika untuk setiap $a \in A,(a, a) \in R$.

Definisi 2.10. [5] Misalkan $A$ adalah himpunan dan $R$ adalah relasi pada $A$. $R$ dikatakan simetris jika untuk setiap $a, b \in A,(b, a) \in R$ bilamana $(a, b) \in R$.

Definisi 2.11. [5] Misalkan $A$ adalah himpunan dan $R$ adalah relasi pada $A$. $R$ dikatakan transitif jika untuk setiap $a, b, c \in A,(a, c) \in R$ bilamana $(a, b) \in R$ dan $(b, c) \in R$.

Definisi 2.12. [5] Misalkan $A$ adalah himpunan dan $R$ adalah relasi pada $A$. $R$ dikatakan relasi ekivalen jika $R$ memenuhi refleksif, simetris, dan transitif. 
Definisi 2.13. [5] Misalkan $A$ adalah himpunan dan $R$ adalah relasi pada A. Kelas ekivalen dari $A$ yang memuat a dinotasikan sebagai $[a]$ yang didefinisikan sebagai himpunan $[a]=\{b \in A \mid(a, b) \in R\}$.

\section{Pembahasan}

\subsection{Presentasi Grup}

Definisi 3.1. [3] Misalkan $X=\left\{x_{1}, x_{2}, \cdots, x_{n}\right\}$ adalah suatu himpunan dan invers dari $X$, ditulis $X^{-1}=\left\{x_{1}^{-1}, x_{2}^{-1}, \cdots, x_{n}^{-1}\right\}$ dan simbol $X^{ \pm 1}$ bermakna $X \cup X^{-1}$. Suatu word $W$ pada $X^{ \pm 1}$ adalah suatu barisan yang berbentuk $x_{1}^{\varepsilon_{1}} x_{2}^{\varepsilon_{2}} \cdots x_{n-1}^{\varepsilon_{n-1}} x_{n}^{\varepsilon_{n}}$, dengan $n \geq 0, x_{i} \in X$ dan $\varepsilon_{i}= \pm 1, i=1,2, \cdots, n$.

Misalkan $W=x_{1}^{\varepsilon_{1}} x_{2}^{\varepsilon_{2}} \cdots x_{n-1}^{\varepsilon_{n-1}} x_{n}^{\varepsilon_{n}}$, panjang dari $W$ adalah bilangan $n$ dan disimbolkan dengan $|W|=n$. Jika $|W|=0$ maka word $W$ dikatakan empty word atau trivial word dan disimbolkan dengan "1". Jelaslah bahwa $|W|=\left|W^{-1}\right|$ dan $\left|W_{1} W_{2}\right|=\left|W_{1}\right|+\left|W_{2}\right|$.

Definisi 3.2. Dua buah word $U$ dan $W$ dikatakan ekivalen secara bebas, jika word $W$ dapat diperoleh dari $U$ dengan sejumlah berhingga operasi penambahan dan/ atau penghapusan pasangan $x_{i}^{\varepsilon_{i}} x_{i}^{-\varepsilon_{i}}, x_{i} \in X, \varepsilon_{i}= \pm 1$. Jika $U$ dan $W$ ekivalen secara bebas, maka disimbolkan dengan $U \sim W$.

Teorema 3.3. [10] Misalkan $F(X)$ himpunan kelas ekivalensi dari word yang relatif pada $X$ berdasarkan relasi $\sim$, maka $F(X)$ adalah grup dengan $[V],[W] \in F(X)$ berlaku operasi biner $[V][W]=[V W]$

Misalkan $G$ adalah grup. Jika pada $G$ didefinisikan suatu himpunan $X$ seperti yang terdapat pada Definisi 3.1 dan terdapat satu atau beberapa word pada $X^{ \pm 1}$ yang sama dengan empty word yang dinamakan himpunan relator dan disimbolkan dengan $R$ ( $R$ adalah himpunan word-word pada $X^{ \pm 1}$ yang sama dengan empty word), maka sistem $\langle X \mid R\rangle$ disebut sebagai presentasi dari $G$, dan biasanya ditulis dengan $G=\langle X \mid R\rangle$, dimana $X$ adalah himpunan generator pada $G$.

\subsection{Presentasi Subgrup dari Representasi Grup Quaternion dan Hasilkali Kronecker}

Kelompok-kelompok subgrup berdasarkan kesamaan perkalian unsur pada tabel perkalian grup.

(1) Subgrup $H_{1}, H_{2}, H_{3}, H_{4}, H_{5}, H_{6}, H_{7}, H_{8}, H_{9}, H_{10}, H_{11}, H_{12}, H_{13}, H_{14}, H_{15}$, $H_{16}, H_{17}, H_{18}, H_{19}$ dengan presentasi subgrup

$$
P_{1}=\left\langle a \mid a^{2}=e\right\rangle .
$$

(2) Subgrup $H_{20}, H_{21}, H_{22}, H_{23}, H_{27}, H_{31}$ dengan presentasi subgrup

$$
P_{2}=\left\langle b \mid b^{4}=e\right\rangle \text {. }
$$

(3) Subgrup $H_{24}, H_{25}, H_{26}, H_{28}, H_{29}, H_{30}, H_{32}, H_{33}, H_{34}$ dengan presentasi subgrup 


$$
P_{3}=\left\langle b, c \mid b^{2}=c^{2}=e,\right\rangle .
$$

(4) Subgrup $H_{35}, H_{54}$ dengan presentasi subgrup

$$
P_{4}=\left\langle b, d \mid b^{4}=e, b^{2}=d^{2}, d b=b d^{-1}\right\rangle .
$$

(5) $H_{37}, H_{39}, H_{41}, H_{43}, H_{45}, H_{47}, H_{49}, H_{51}, H_{53}, H_{55}, H_{56}, H_{57}, H_{58}, H_{59}, H_{62}$, $H_{64}, H_{66}, H_{69}$ dengan presentasi subgrup

$$
P_{5}=\left\langle b, d \mid b^{4}=d^{2}=e, d b=b d^{-1}\right\rangle .
$$

(6) Subgrup $H_{36}, H_{38}, H_{40}, H_{42}, H_{44}, H_{46}, H_{48}, H_{50}, H_{52}$ dengan presentasi subgrup

$$
P_{6}=\left\langle b, d \mid b^{4}=e, b^{2}=d^{2} d b=b d\right\rangle .
$$

(7) Subgrup $H_{60}, H_{61}, H_{63}, H_{65}, H_{67}, H_{68}$ dengan presentasi subgrup

$$
P_{7}=\left\langle a, b, d \mid a^{2}=b^{2}=d^{2}=e, a b d=b d a\right\rangle .
$$

(8) Subgrup $H_{70}, H_{71}, H_{72}, H_{73}$ dengan presentasi subgrup

$$
P_{8}=\left\langle i, k, m \mid i^{4}=k^{2}=m^{2}=e, m k i=i k m^{-1}\right\rangle .
$$

\section{Kesimpulan}

Presentasi-presentasi subgrup yang diperoleh memiliki tiga tipe dalam banyak unsur pada generatornya yaitu presentasi subgrup yang memiliki generator berunsur 1, 2 dan 3. Adapun presentasi subgrup yang memiliki satu unsur pada generatornya adalah $P_{1}$ dan $P_{2}$. Presentasi yang diperoleh ini juga memenuhi definisi dari suatu grup yaitu grup siklik. Grup siklik adalah grup yang dibangun oleh satu unsur $a$ pada generator dengan relator nya adalah word $a^{n}$ dengan banyak unsur dalam grup adalah sebanyak $n$ unsur.

Presentasi subgrup yang memiliki dua unsur pada generatornya adalah $P_{3}, P_{4}$, $P_{5}$ dan $P_{6}$. Presentasi $P_{3}$ dan $P_{4}$ adalah presentasi dari subgrup berorde empat dan delapan yang mana subgrup ini adalah subgrup abelian. Presentasi $P_{5}$ adalah presentasi yang memenuhi sifat grup quaternion, sedangkan presentasi $P_{6}$ adalah presentasi yang memenuhi sifat grup dehidral yaitu $D_{8}$. Grup dehidral adalah grup yang dibangun oleh dua unsur $a, b$ pada gene-ratornya dengan relatornya adalah word $a^{n}, b^{2}$ dan $d b d b^{-1}$. Notasi grup ini adalah $D_{2 n}$ dengan banyak unsur sebanyak $2 n$.

Presentasi subgrup yang memiliki tiga unsur pada generatornya adalah $P_{7}$ dan $P_{8}$. Presentasi $P_{7}$ adalah presentasi subgrup berorde 8 yang abelian dan $P_{8}$ adalah presentasi subgrup berorde 16 .

\section{Ucapan Terima kasih}

Terima kasih kepada ibu Nova Noliza Bakar, M.Si, bapak Dr. Admi Nazra, dan ibu Dr. Haripamyu, selaku dosen penguji, yang telah memberikan kritik dan saran dalam penulisan makalah ini. 


\section{Daftar Pustaka}

[1] Dummit, D.S dan Foote, R.M. 1991. Abstract Algebra. Prentice-Hall. New Jersey

[2] Yanita; Helmi, M.R dan Zakiya, A. 2018. Solvability Group From Kronecker Product on the Representation of Quaternion Group.

Akan terbit di Asian Journal of Scientific Sciences. http://docsdrive.com/pdfs/ansinet/ajsr/0000/92123-92123.pdf

[3] Parshin, A. N dan Shafarevich, I. R. 1993. Combinatorial Group Theory. Applications to Geometri. Encyclopaedia of Mathematical Sciences. Vol 58 : 260

[4] Roman, S. 2012. Fundamentals of Group Theory. Springer Science+Business Media, LLC. New York

[5] Chen, W. W. L. 2008. Discrete Mathematics. Lecture Note. University of London

[6] Huamin, Z dan Feng, D. 2013. On the Kronecker Products and Their Applications. Journal of Applied Mathematics. vol. 2013. pp 1 - 8 .

[7] Hadley, G. 1961. Linear Algebra. Terjemahan Naipospos dan Noeniek(1983). Erlangga. Jakarta.

[8] James, G dan Liebeck, M. 2001. Representations and Characters of Groups. Cambridge University Press. Cambridge.

[9] Van der Waerden, B. L. 1976. Hamilton's Discovery of Quaternions. Mathematics Magazine, 49 (5) : 227 - 234.

[10] Magnus, W; Karrass, A dan Solitar, D. 1976. Combinatorial Group Theory. Dover Publications, Inc. New York. 